\title{
The relevance of surveying content in mining engineering education
}

\author{
P.O. Oshokoya ${ }^{1}$ and S. Naidoo ${ }^{2}$
}

\begin{abstract}
${ }^{1}$ Lecturer and corresponding author. School of Mining Engineering, University of the Witwatersrand, Johannesburg, South Africa. Email: tomi.oshokoya@wits.ac.za. Telephone: +27 (011) 7177429 .

${ }^{2}$ Lecturer. School of Mining Engineering, University of the Witwatersrand, Johannesburg, South Africa.
\end{abstract}

DOI: http://dx.doi.org/10.4314/sajg.v3i2.9

\begin{abstract}
The University of the Witwatersrand School of Mining Engineering (Wits Mining) has its origins in the South African School of Mines, which was established in 1896. It is currently recognised as one of the world's top mining engineering schools that educate mining engineering candidates to become qualified to specialise in a variety of disciplines required in a modern mining environment. At undergraduate level, Wits mining offers one degree programme - B.Sc. in mining engineering. The role of Wits Mining has been one of successfully facilitating the continuous professional development of mining engineers and mining specialists like mine surveyors.

The paper will highlight the surveying content that is relevant to the mining engineering programme according to the Engineering Council of South Africa (ECSA) by show-casing the surveying content within the Wits Mining programme and comparing this with what is obtainable at other international schools of mining engineering, such as Aachen University (Germany), the University of Mines and Technology (Ghana) and the University of Johannesburg (South Africa). The training of mine surveyors is well established in South Africa, and Wits University is an institution where a mine surveyor can obtain a Master's degree specialising in any one of 5 mining specialisations, including Mine Surveying. This article attempts to answer the question as to what mining engineers should know about mine surveying. The paper will also explain how mine surveying training is beneficial to a mining engineer's career development.
\end{abstract}

Keywords: Education, specialisation, degree programme, Wits mining

\section{Introduction}

The profession of Mining Engineering is concerned with the safe, effective, profitable and environmentally responsible operation of mineral extraction in order to meet the ever-expanding demand from the global community for mineral commodities (UNSW, 2013). Mining engineers are 
required to supervise any phase of the mining process, which can be influenced by computing and information technology, globalisation, economic reforms and environmental considerations. These factors require mining engineering to be a multifaceted discipline (GoStudy, 2013). Similarly, the role of the modern mine surveyor has diversified such that he or she is involved with the surveying and mapping of surface and underground mine workings, legalities of boundaries, mine planning, local and regional development, mine closure processes and information systems (Schulte \& Mathey, 2010). In practice, the entire mining process necessitates the call for the mining engineer to possess diverse skillsets, including modern surveying practices.

Therefore, to undertake the responsibilities of the mining engineering profession, a broad educational background that incorporates aspects of other disciplines such as geology, civil, mechanical and electrical engineering, surveying, marketing and financial management of mineral resources is required (UNSW, 2013). A sound knowledge-base must also include mathematical science, basic engineering science and its application, current practices in mining engineering, economic considerations, and health and safety requirements (Wits Mining, 2012). Mining engineering education must therefore offer a broad knowledge-base, which can lead to a wide range of career paths.

With the plethora of related degree choices and institutions offering these degrees, it becomes ever more important to be aware of what the industry requires and what is offered by institutions providing mining-related education. The purpose of this paper is to provide a comprehensive overview of mining education at Wits and other comparable mining institutions in order to facilitate the awareness of the changes in the mining industry with respect to mine surveying. Ultimately, the understanding gained from this paper will be a guide for both new entrants into the mining engineering and mine surveying disciplines as well as developing professionals.

\section{A short history of survey education within the School of Mining Engineering.}

From the 1920's to the 1940's, there was a survey school within the School of Mining Engineering, offering mine surveying and land surveying subjects. In the 1980's, student numbers declined and talks began about closing the surveying programme (Phillips, 2013). Subsequently, the surveying degree was incorporated under a Bachelor's degree in Mineral Resource Management (MRM), because the industry began to perceive a professional mine surveyor's role as a mineral resource manager who uses data collected by survey technicians. After this development, there was no longer a survey department but surveying as a subject was offered to students as part of their core knowledge-base (Phillips, 2013). The few students enrolled in the land surveying degree were assisted to transfer to the other universities that were still offering surveying as a specialist subject at undergraduate level. The School of Mining Engineering was therefore split between Mining Engineering and the MRM programme. However, the MRM programme started to lose student numbers with students converting their MRM degree to a Mining Engineering degree as it was 
perceived to offer better and broader career prospects. In 1991, the MRM degree programme was also phased out. Both the mine surveying and MRM programmes have since been offered by the University of Johannesburg (UJ) through a combination of National Diploma (N.Dip) and Bachelor of Technology (B.Tech) degrees. Today, Wits Mining offers one undergraduate degree, a Bachelor of Science (B.Sc.) in Mining Engineering and it is the largest mining school in the English-speaking world with a student body in excess of 760 students, about $22 \%$ of which are at a postgraduate level studying towards an M.Sc. or Ph.D. degree (School of Mining Engineering, 2014).

Wits Mining provides quality training and education of mining engineers who may want to specialise in a number of mining-related expertise. The educational objectives of its mining engineering degree is to equip candidates with the necessary knowledge, understanding and the development of certain abilities, attitudes and experience, which would prepare them to register as professional mining engineers (Wits School of Mining Engineering, 2012). Embedded in the educational objectives of Wits Mining is the encouragement of further learning towards becoming a competent practicing engineer. The School offers a number of courses at undergraduate level, which will assist in the development of skills to obtain and manage information efficiently, to think clearly, to make decisions, to be creative and to communicate effectively. This foundation assists the candidates at postgraduate level, where courses in applied engineering and specialist areas of professionalism are taught. This educational process is comparable with international schools offering mining engineering education.

\subsection{What does Wits offer with regards to mine surveying?}

In the School, the courses offered in the mining engineering programme are structured such that each year prepares the student for the role of a mining engineer with a choice to specialise in a number of mining disciplines at a postgraduate level, either within Wits Mining or at any other tertiary institution which recognises its accreditation. With regards to mining operations such as mine planning, design, construction, monitoring of mine structures, a professional mine surveyor's role involves data collection and processing for the realisation of adequate mineral resource management. All mining engineering and mine surveying operations require a sound knowledge of mathematics, basic, physical and engineering sciences, which form the foundation on which the curriculum for any engineering degree is based. The School offers these fundamental mathematical and related science courses at undergraduate level in year one and two.

Mine surveying skills are built on the knowledge-base of the first and second year of study. In first year, the courses offered that provide a sound base towards this end are Mining Graphics and Design (MINN1000) and Engineering Skills (MINN1001). The aim of these courses is to provide the students with a firm grounding to ensure that they are adequately prepared to communicate effectively, both graphically and verbally, within an engineering environment. The two courses cover content relating to basic drawing skills that include: scales, simple map projections, geometrical construction of a grid, scale bars and diagonal scales that are used for producing 
graphic documents (such as plans, maps, sections and profiles). They also cover rectangular and polar coordinate calculations, area and volume calculations, trigonometry, circle geometry, spatial positioning, sketching, orthogonal projections, contours and interpolation, superimposition of design contours and cut/fill lines, 3-D drawing, longitudinal profiles and cross-sections and interpretation of maps (Wits Mining, 2012). These two courses taken in the first year are the foundations for preparing students for acquiring mine surveying skills in their academic career at Wits Mining. Figure 1 shows the percentage contribution of the surveying content to the total first year mining engineering programme.

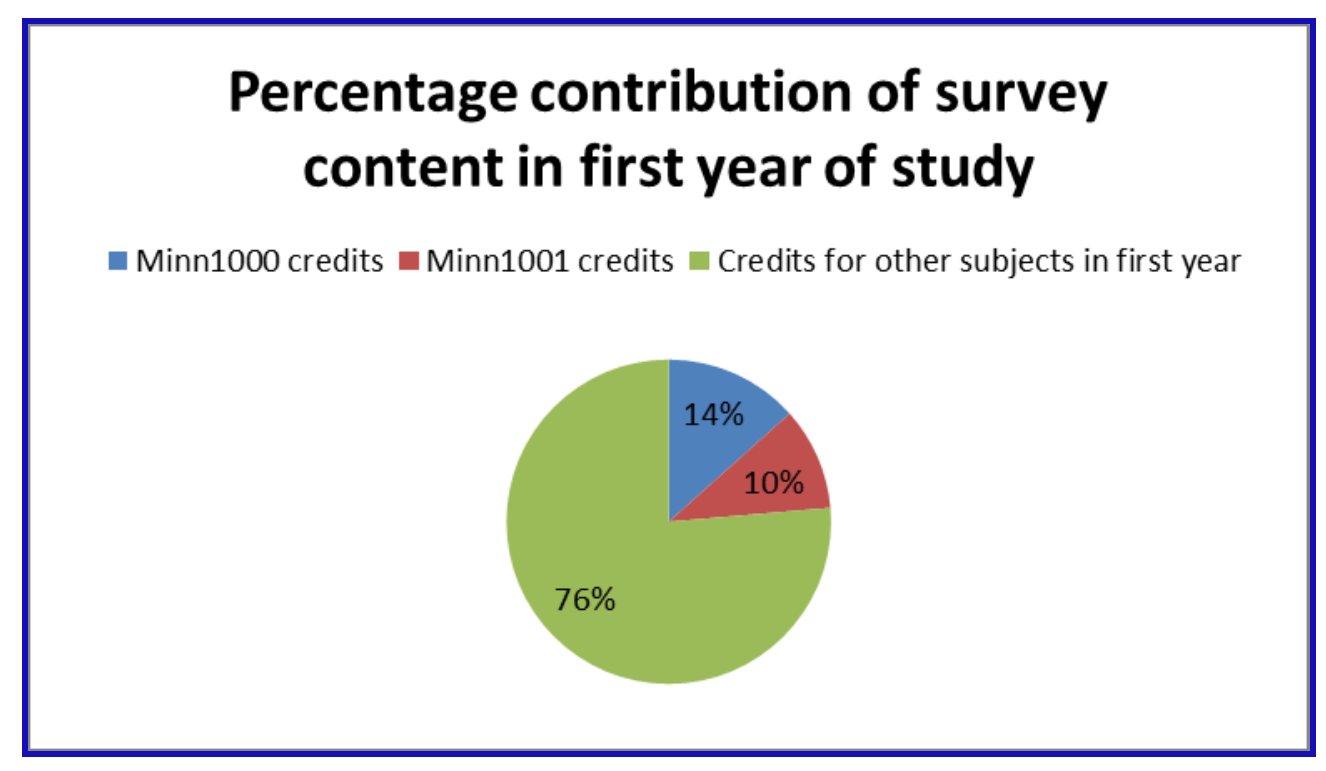

Figure 1: Percentage contribution of surveying content in first year of study.

It can be observed from Figure 1 that the combination of the percentage contributions of the surveying-related courses represents $24 \%$ of total credits of first year mining studies. This implies significant surveying content at the initial stage of a student's acquisition of mine surveying skills. Likewise, in order to progressively enable students to obtain the correct foundation needed to become competent in the mine surveying discipline, Engineering Surveying (MINN2004) is taught in the second year of study. The purpose of this course is to facilitate the student's acquisition of skills in the use of survey instruments, the recording and transfer of readings both manually and electronically, the processing of results and error analysis (Wits Mining, 2013). The course covers an overview of what surveying is, its principles, surveying instrumentation and surveying techniques. Other areas covered in this course include setting out, longitudinal and cross sections, cut and fill and mass-haul diagrams, areas and volumes calculations, the South African co-ordinate system, use of contouring and computer-aided draughting, design and cartography software as well as hand-held and survey GPS systems. The students are equipped with the knowledge and ability needed for gathering field information, in a practical way. Figure 2 indicates the percentage contribution of the surveying content to the total second year mining engineering programme. 


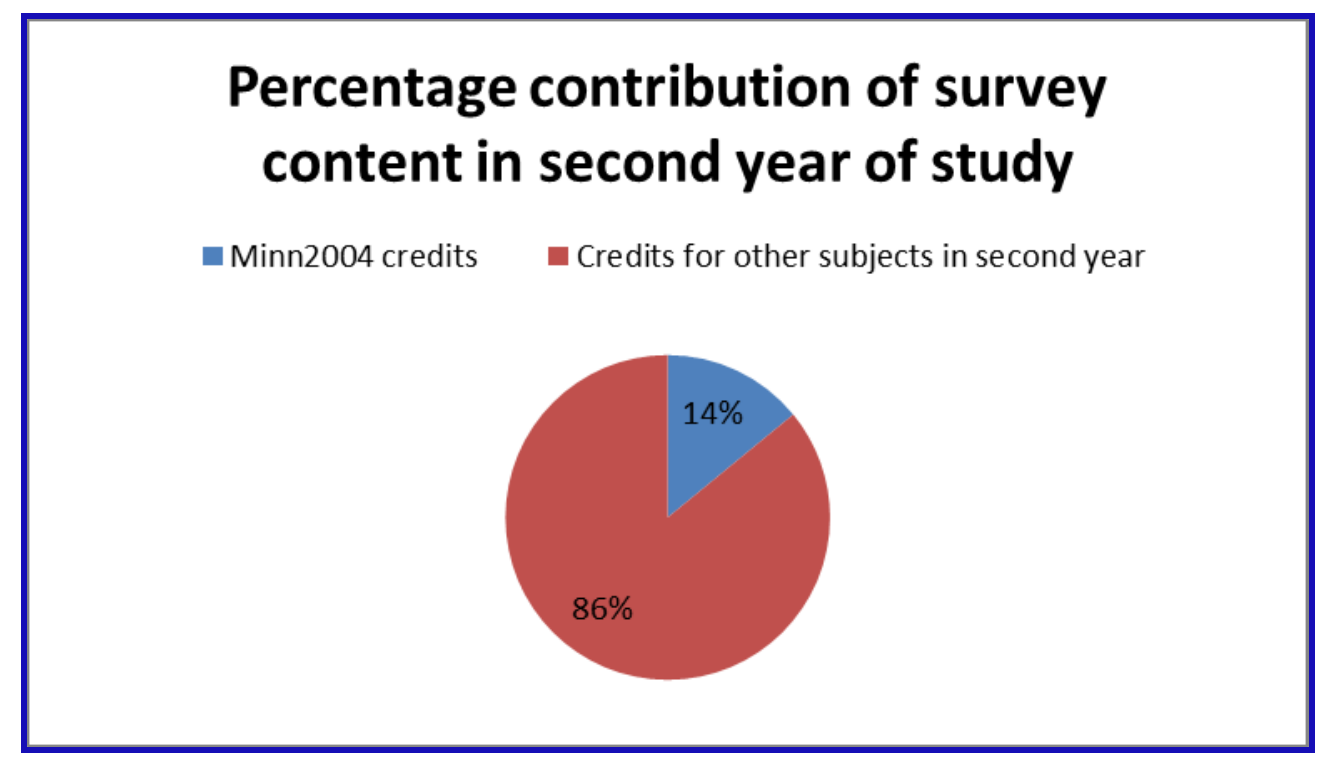

Figure 2: Percentage contribution of surveying content in second year of study.

Figure 2 shows that the proportion of the second year mining undergraduate programme that MINN2004 covers is also significant especially when viewed in light of its combination with surveying content of the first year programme. MINN2004 equips candidates to be competent in land surveying, which assists them on their educational journey towards mine surveying.

In the third year of study, Mine Surveying (MINN3012) is introduced to mining engineering students. This module is an introduction to the importance of mine surveying in the efficient and safe running of a mine. It further covers topics that show how the principles of land surveying relate to mine surveying, transferring of surface surveys to the underground environment, underground mine surveying methods and their applications to mine planning, design and safety. Other areas covered in this course include understanding survey-related legal requirements and their application to the mining industry; combining mathematical and surveying principles for solving three dimensional mine design problems; interpretation of mine surveying results for improved decision making on a mine (FEBE, 2013). It must be noted that Engineering Surveying and Mine surveying are not purely theoretical disciplines but require on-site operations to obtain survey data from the field. Therefore in these courses, practical sessions are major components. These practical sessions involve distance and angular measurements through the means of survey techniques such as traversing (with tape and total stations), levelling, vertical surveys and the use of a gyro-theodolite to determine azimuth. Survey observations made are processed, measurement errors are treated, and data are recorded in terms of the mining legislations. These data are represented numerically and/or graphically for general land surveying and mine surveying applications. In Figure 3, the percentage contribution of surveying content to the total third year mining engineering programme is illustrated. 


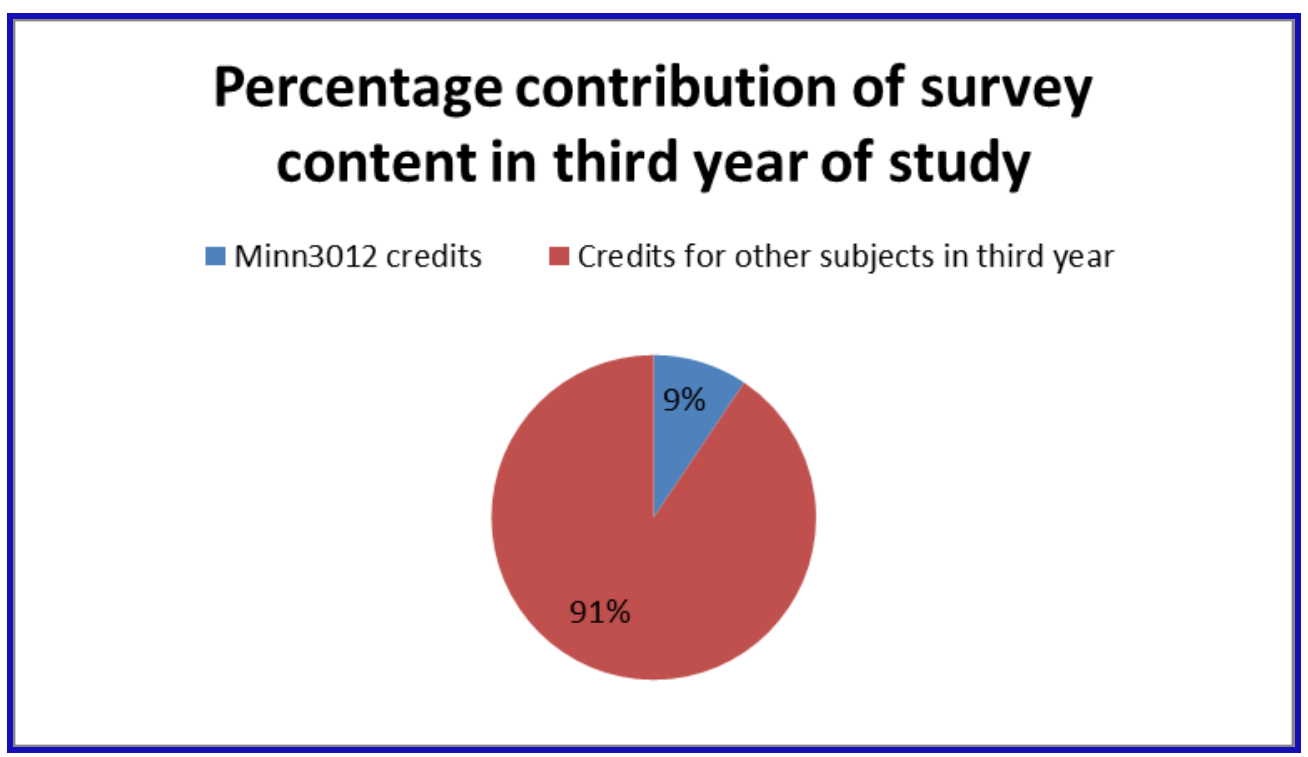

Figure 3: Percentage contribution of surveying content in third year of study.

By combing all the surveying components of first, second and third years together, figure 4 illustrates that these courses comprise of approximately 10 percent of the entire four-year mining undergraduate programme.

\section{$\%$ Contribution of Survey content - comparison}

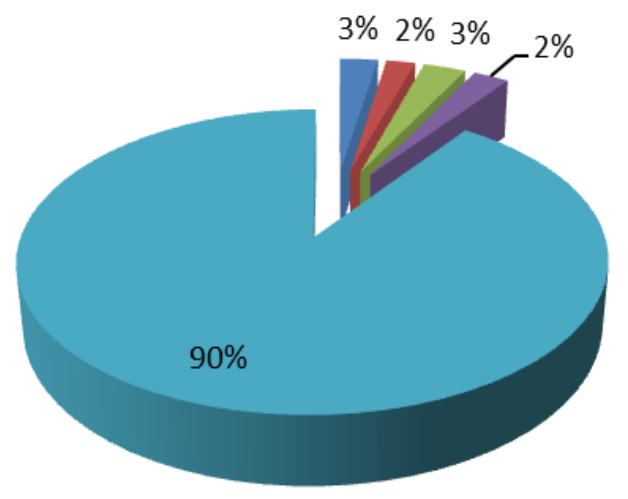

1st year (Minn1000)

- 1st year (Minn1001)

2nd year (Minn 2004)

- 3rd year(Minn 3012)

Entire B.Sc. Mining degree

Figure 4: The percentage contribution of all the surveying courses of the four-year B.Sc. (Mining Engineering) programme.

A significant proportion taken up by the surveying-related subjects in the course structure of the undergraduate programme indicates that the School meets the expectation that Wits Mining engineering graduates must have competencies in associated mining disciplines. The undergraduate (B.Sc.) degree is structured to adequately prepare students for careers in engineering and related areas, to ensure that they are equipped with problem-solving and teamwork skills, the ability to 
show technical leadership as well as the ability to make responsible contributions to the economy and societal development. The B.Sc. degree satisfies the educational requirements necessary for registration as a Professional Engineer with the Engineering Council of South Africa (Wits School of Mining Engineering, 2012).

The Engineering Council of South Africa (ECSA) is a statutory body responsible for promoting a high level of education and training of practitioners in the engineering profession so as to facilitate the full recognition of the profession, both locally and internationally (Engineering Council Of South Africa , 2012). ECSA evaluates the engineering education offered by any South African tertiary institution and makes a decision on whether its engineering programme(s) meets the educational requirements needed to allow its graduates to be recognised for registration with the body. As part of its criteria for granting accreditation for any engineering programme, ECSA specifies 10 Exit Level Outcomes (ELO's) that each candidate is expected to achieve on completion of the engineering degree/programme. The ELO's include the use of mathematics, basic sciences and engineering sciences; investigation, experiments and data analysis; engineering methods, skills, tools and information technology; professional and general communication; team and multidisciplinary working; and lifelong (independent) learning (Wits School of Mining Engineering, 2012). Final ELO's are assessed at the third and/or fourth years of study, while first and second years of study provide development towards this final assessment. The mine surveyingrelated courses offered at Wits Mining are designed to satisfy these ELO's. Similarly, the South African Council for Professional and Technical Surveyors (PLATO) is a professional registration body that evaluates and accredits mine surveying programmes. With the accreditation process offered through PLATO, postgraduate students can transfer to Wits Mining for further specialization and development.

The School encourages its students to develop a habit of learning in order to keep up with the rapid advances in technology and in discipline related knowledge, within the mining industry and affiliated industries (Wits School of Mining Engineering, 2012). Its undergraduate degree programme is therefore also structured to allow for a coherent natural progression to postgraduate studies in both course-based and research Masters programmes. Due to mining engineering's broad coverage, Areas of Specialisation (AOS) are available at Wits Mining, at postgraduate level (Wits Mining Postgraduate, 2013). These specialist study programmes build on a strong foundation of mathematics, science and engineering sciences presented in the undergraduate level of study. The school admits candidates with mining engineering and mine surveying undergraduate degrees from other accredited tertiary institutions such as the University of Johannesburg, into their Masters programme for advancing their professional studies in an AOS offered. The AOS available to candidates with mine surveying education are Mineral Economics, Mineral Resource Management (MRM), Mineral Resource Evaluation (MRE), Mine Planning and Optimisation and Mine Surveying (Wits Mining Postgraduate, 2013). 
It is important to note that candidates who have undergone the Wits Mining undergraduate education (registered with ECSA) and other mine surveying educated candidates (registered with PLATO), who decide to specialise in MRM or MRE under the Wits Mining postgraduate programme, are enabled to satisfy one of the requirements to be called a "Competent Person" (SAMREC code) or "Competent Valuator" (SAMVAL code).

\section{Comparability of Wits Mining's surveying education with international counterparts.}

The aim of this section is to identify what one can obtain with respect to surveying education in other mining schools, both internationally and locally. The end result of this assessment is to draw lessons from which the Schools and their students can benefit. The Schools used for comparability assessment of this paper include RWTH Aachen University (Germany), The University of Mines and Technology (Ghana), and The University of Johannesburg (South Africa). The small sample of Schools used in this paper's assessment is for the purpose of showing a general overview of surveying education in a mining engineering context, at undergraduate level.

\subsection{The education of young professionals at RWTH Aachen University}

RWTH Aachen University in Germany offers a three-year undergraduate B.Sc. degree in Mineral Resources Engineering. The programme is structured so that there is specialisation in mine surveying, mining engineering or mineral processing offered in the second year of the B.Sc. degree and in the second year of the M.Sc. programme. The subjects offered in the first year of the Mineral Resources Engineering degree was offered after a reformation and conversion process that started in 2005, which merged formerly separate diplomas. According to Schulte \& Mathey (2010), "the intention was such that students of the new system should look into the fundamentals of any mining related matters to gain broader knowledge and not only a specific education in one of the studies". As of 2010, the Mining Engineering and Mine Surveying degrees have merged into one degree such that future mine surveyors will be educated as mining engineers with a choice to further specialise in the competencies of a mine surveyor. The new degree package therefore offers a broad-based knowledge of mining and mining related skills which will equip both the mining engineer and the modern mine surveyor with the broad knowledge base and the diverse skills required for a multifaceted career in the mining industry and related fields, both in Germany and globally. This reformation was in part due to the fact that a modern German mine surveyor has seen a career development towards being a generalist in mining and adjacent fields of activity (Schulte \& Mathey, 2010). 


\subsection{Survey education at the University of Mines and Technology (Ghana)}

Surveying education is offered by the Department of Geomatic Engineering at the University of Mines and Technology (UMaT). This department was created when the Mine Surveying section of the Department of Geology and Survey at the then Tarkwa School of Mines (TSM) was upgraded to the Geomatic Engineering department (Duncan and Djaba, 2005). Invariably, this upgrade led to its Diploma programme in Mine Surveying being also 'upgraded' to the status of a B.Sc. programme in Geomatic Engineering. The reorganisation resulted in TSM becoming UMaT in 2004. The Geomatic Engineering Department is currently one of the five academic departments offering fouryear B.Sc. programmes at UMaT's Faculty of Mineral Resources Technology (UMaT, 2014).

The Geomatic Engineering education programme offered by UMaT reflects the changes in the survey profession, because of advances in computer science, information technology and survey instrumentation. The Geomatics Engineering Department aims at providing students with knowledge in a wide range of activities required for the geometric measurements (surveying) of the earth's surface (UMaT Geomatic Engineering, 2014). The degree programme is multi-disciplinary, covering various methods and techniques of acquiring, processing of geospatial data from air, land, water-bodies and underground. The programme is also structured to provide training on the visualization and setting out of the acquired data in the form of designs, maps and plans in hard or soft copies for the delineation of natural resources, planning, engineering construction and land administration/registration purposes.

Although the Department's main focus is on training students to possess skills needed in the areas of land surveying, geodetic surveying, cadastral surveying, engineering surveying, mine surveying, remote sensing, Geographic Information Systems (GIS), digital mapping and Global Positioning Systems (GPS), its mining roots have not been ignored in its course structure. The curriculum also includes mining-related courses in the third and fourth years of study (UMaT Geomatic Engineering, 2014). Also, the mining engineering programme offered by the Mining Engineering Department at the Faculty of Mineral Resources Technology contains a significant amount of surveying course content. This is due to the fact that the courses offered in the programme require a strong knowledge base in, amongst other academic disciplines, land surveying and GIS. In the second, third and fourth years of studies, students are required to enrol for further surveying courses including land surveying, mine surveying, survey field work and GIS (UMaT Mining Engineering, 2014).

From the above discussion, it is apparent that the goal of the upgrade of the Geomatic Engineering Department was not only to ensure broader opportunities for its graduates, but also to reflect the current changes in the surveying profession. In this way, the graduates from the department are equipped with broad-based, analytical and intellectual skills in the application of the necessary technologies, methodologies and equipment necessary for working under rapidly changing environments. They are also armed with good management and entrepreneurial skills. On completion of the Geomatic Engineering degree, in order for the graduate to be recognised fully by 
law as a professional land surveyor, he/she is required to be a member of the Ghana Institution of Surveyors (GhIS). The GhIS is the recognized professional body that regulates the profession of surveying and its practice in Ghana. On the other hand, the graduate from the Mining Engineering Department of UMaT needs to become a member of the Ghana Institution of Engineers (GhIE) for professional recognition. The curricula of both UMaT's Geomatic Engineering and Mining Engineering Departments offer courses that provide broad-based surveying training coupled with mining-related courses.

\subsection{Survey education at the University of Johannesburg}

The University of Johannesburg (UJ) has a Department of Mining Engineering and a Department of Minerals Surveying within the Faculty of Engineering. The Department of Mining Engineering offers formal tuition towards the National Diploma (N.Dip) and Bachelor of Technology (B.Tech) in Mining Engineering. The Department of Minerals Surveying offers undergraduates a National Diploma in Minerals Surveying, which is also a three year programme.

In spite of the exposure to mine surveying subjects in the third and fourth years of study, it should be noted that the graduate with an N.Dip or a B.Tech degree in Mining Engineering cannot register with PLATO as a Professional Mine Surveyor in-training. He/she may train towards the Government Certificate of Competency, which would enable him or her to qualify as a Professional Mine Surveyor. However, this is unlikely because of better career prospects in mining. In other words, the choice of path in the first degree normally determines the professional options open to the student on completion of an N.Dip, B.Sc. or M.Sc. degree. The Department of Minerals Surveying at UJ is the only institution in South Africa that offers undergraduate training towards a career path as a certified Professional Mine Surveyor. After graduation from this programme, the graduate can register with PLATO as a "Technician" in Minerals Surveying and is eligible to further his or her study in a B.Tech degree as the next step of their career path. A one year B.Tech degree could enable a graduate to register with PLATO as a "Technologist in training towards a Professional Mine Surveyor. Graduates with a B.Tech degree may continue their studies and enrol for a Masters in Technology (M.Tech). The M.Tech degree can be followed by a Doctorate in Technology (D.Tech) in Minerals Surveying (UJ Mine Surveying, 2014). The PLATO-registered graduate can practise in the South African mining industry on completion of the Government Certificate of Competency administered by the Directorate of Mineral Resources (DMR). This certificate remains the exclusive licence to practice mine surveying on a mine.

Students who are contemplating a career in purely mine surveying would be good candidates for the B.Tech Minerals Surveying degree at UJ. 


\section{Conclusion and recommendation}

The role of the mining professional is diversified, and this career development has necessitated the education of a mining engineer to have a broad-base of knowledge and skills that can enable a further specialisation in areas such as mine surveying. The mining industry requires graduates to possess adequate competencies. Wits Mining facilitates this course of study by designing its undergraduate degree programme to provide a broad knowledge base and skills acquisition in associated competencies such as mine surveying. With this foundation at undergraduate level, the graduate can choose a mine surveying career path at any accredited tertiary institution which offers mine surveying as a specialisation at M.Sc. level. The degree in mining engineering offered by Wits, UMaT, UJ and RWTH Aachen University supports and enables mining engineers to follow a mine surveying career path by allowing further specialisation in this area. In South Africa, the mining engineering candidate must note that his/her undergraduate degree determines the options for professional status, both locally and internationally. A Wits graduate can register as a professional mining engineer with ECSA, but is not recognized as a professional mine surveyor by PLATO. The Wits degree equips students to specialise in surveying at a Masters level and to function competently in the mine surveying discipline by enabling recognition as a 'Competent Person' and 'Competent Valuator'.

The knowledge and skills taught to mining engineers at Wits Mining reflects what mining engineers need to know about mine surveying. This in turn reflects the multifaceted roles of both a mining engineer and mine surveyor in the industry. The surveying content in the mining engineering programme is essential because surveying concepts help to strengthen the mining engineer's ability to perform calculations and to excel in problem-solving. Amongst other things, surveying subjects assist in developing the competency of 3D visualisation - an essential skill of an engineer. Mine managers specifically need to appreciate the importance of the mine surveyor's role, because 'if one cannot measure something (that is, apply surveying skills), one cannot manage it'.

\section{References}

\section{Web document}

Duncan, E.E. and Djaba, S., 2005. Geomatic Engineering education at the University of Mines and Technology (UMaT), Ghana.A publication for 'From Pharaohs to Geoinformatics', FIG Working Week 2005 and GSDI-8 Cairo, Egypt April 16-21, 2005. Available at: http://www.fig.net/pub/cairo/papers/ts_20/ts20_03_duncan_djaba.pdf

Engineering Council Of South Africa, 2012. About ECSA: What Is ECSA? Available at: http://www.ecsa.co.za/index.asp?x=ecsa. 


\section{Website}

GoStudy, 2013. Mining Engineer. Available at: http://www.gostudy.mobi/careers/View.aspx?oid=196

UJ Mine Surveying, 2014. 'Department of Mine Surveying'. Available at: http://www.uj.ac.za/EN/Faculties/engineering/departments/minesurv/Pages/default.aspx.

UJ Mining Engineering, 2014. 'Department of Mining Engineering'. Available at: http://www.uj.ac.za/EN/Faculties/engineering/departments/mining/Pages/default.aspx

UMaT Geomatic Engineering, 2014. 'Geomatic Engineering'. Available at: http://umat.edu.gh/geomatic-engineering.html?showall=1

UMaT Mining Engineering, 2014. 'Mining Engineering'. Available at: http://umat.edu.gh/miningengineering.html? showall $=1$

UMaT, 2014. 'About us - University of Mines and Technology (UMaT), Tarkwa. Ghana'. Available at: http://umat.edu.gh/about-us/about-umat.html

UNSW, 2013. School of Mining Engineering: What is Mining Engineering. Available at: http://www.mining.unsw.edu.au/information-for/future-students/future-undergraduates/whatmining

\section{Report}

School of Mining Engineering, 2014. Wits School of Mining Engineering Annual Report 2013. University of the Witwatersrand, Johannesburg, South Africa.

FEBE, 2013. Wits Rules and Syllabuses - Faculty of Engineering and the Built Environment, Johannesburg, South Africa: University of the Witwatersrand.

Wits Mining Postgraduate, 2013. School of Mining Engineering Postgraduate Handbook, Johannesburg: University of the Witwatersrand, School of Mining Engineering.

Wits Mining, 2012. MINN1001: Engineering Skills (Mining) Course Outline, Johannesburg: University of the Witwatersrand School of Mining Engineering.

Wits Mining, 2013. MINN 2004: Engineering Surveying Course Outline, Johannesburg: University of the Witwatersrand School of Mining Engineering.

Wits School of Mining Engineering, 2012. Report for the accreditation visit by ECSA, Johannesburg, South Africa: University of the Witwatersrand, School of Mining Engineering. 
South African Journal of Geomatics, Vol. 3, No. 2, August 2014

\section{Personal Communication}

Phillips, H., 2013. Professor [Interview] (February 2013).

\section{Journal article}

Schulte \& Mathey, 2010. The Education of Modern Mine Surveyors as Generalists in Mining in Germany. Sun City, Johannesburg, ISBN: 978-0-620-48540-1, p. 5. 